\title{
Radical Perineal Prostatectomy and Early Continence: Outcomes after 120 Cases
}

\author{
Selami Albayrak, Onder Canguven, Cemal Goktas, Cihangir Cetinel, Rahim Horuz, Huseyin \\ Aydemir
}

Urology II Clinics (SA, OC, CG, CC), Kartal Teaching and Research Hospital, Istanbul, Turkey, Osmaniye State Hospital (RH), Osmaniye, Turkey and Muradiye State Hospital (HA), Van, Turkey

\begin{abstract}
Purpose: Evaluate the results of urinary continence on patients who had undergone radical perineal prostatectomy (RPP) for clinically localized prostate cancer.

Materials and Methods: We analyzed the continence data of 120 patients with pathology of cT1-cT2N0M0 prostate cancer and who had undergone RPP. Continence was assessed on the day of catheter removal, at the end of the first and third month, and the first year postoperatively. The patients who were continent immediately after catheter removal were classified in the group of "immediately continent" while the patients who became continent during the 3 postoperative months were classified as "early continent."

Results: Mean duration of catheterization was 10 (10-25) days. Of 120 patients, 44 (36.7\%) were immediately continent. At the end of the first and third months, 65 (54.1\%) and 87 (72.5\%), respectively, were early continent. At the one-year follow-up, $95.3 \%$ of 107 cases whose one-year follow-up data were available were continent. When the relationship between patients' age and continence was analyzed, it was found that the early continence rates were 77.7\% (7/9), 73.3\% (33/45), $73.4 \%(36 / 49)$, and $64.7 \%(11 / 17)$ in the groups of $\leq 49,50-59,60-69$, and $\geq 70$ years, respectively $(p=0.68)$.

Conclusions: The majority of patients who underwent RPP rapidly regained continence within 3 months. RPP is an exceptional alternative approach for radical surgery in the treatment of localized prostate cancer.
\end{abstract}

Key words: perineum; prostatectomy; prostatic neoplasms; urinary incontinence

Int Braz, J Urol. 2010; 36: 693-9

\section{INTRODUCTION}

Prostate cancer is the most common malignancy and the second leading cause of cancer death in men (1). Active treatment is usually recommended for patients with localized disease and a long life expectancy, with radical prostatectomy (RP) being shown to be superior to other treatments in appropriate patients. Because the urologists always seek less invasive and less morbid therapeutic options and the financial sources supplying health worldwide tend to support therapeutic modalities resulting in shorter hospitalization and early recovery, interest in radical perineal prostatectomy (RPP) has increased again in recent years $(1,2)$. When compared to radical retropubic prostatectomy (RRP), laparoscopic or roboticassisted procedures have advantageous outcome data regarding duration of hospitalization, loss of blood, time needed to recover from the disease, and return to normal daily life (3). However, these advantages may also be offered by RPP, which additionally has some advantages such as lesser cost and shorter duration of 
operation $(1,4)$. RPP also presents an optimal exposure for apical dissection and urethrovesical anastomosis (4).

Post-RP urinary incontinence rates have decreased with the ability to detect the disease in relatively early stages and with the development of new techniques. On the other hand, because the RP surgeries are constantly increasing all over the world, the prevalence of post-RP incontinence has probably increased (5).

Studies have demonstrated no significant difference in the rates of urinary incontinence between patients who had undergone RPP and those who had undergone RRP $(6,7)$. However, there are few studies of a limited number of patients exploring the effect of RPP on early urinary continence in the literature $(1,2)$. In this study, we evaluated urinary continence data of our localized prostate cancer cases who had undergone RPP by single surgeon.

\section{MATERIALS AND METHODS}

We evaluated early continence results for 120 consecutive patients with the diagnosis of localized prostate cancer who had undergone RPP performed by single surgeon in our clinic between March 2004 and September 2009. The patients whose prostate volume was $<60$ cc with a Gleason score $\leq 7(3+4) / 10$ and PSA level $<10 \mathrm{ng} / \mathrm{mL}$ were accepted as eligible for RPP. The Partin nomogram (8) was used before the $\mathrm{RP}$ to predict the status of pelvic nodal metastasis. The patients with a probability of nodal metastasis of $>5 \%$ were excluded from RPP group. Of the patients with a significant risk of pelvic node metastasis, those in whom retropubic approach was considered difficult underwent laparoscopic pelvic lymph node dissection (LPLND), and RPP was performed in the patients whose lymph nodes were reported as negative.

All RPP was performed through Belt's subsphincteric route (4) and, whenever possible, unilateral or bilateral nerve sparing techniques were applied according to peroperative findings. Urethrovesical anastomosis was done using 4/0 double-needle PDS sutures, starting from the point of 12 o'clock and running either direction toward 6 o'clock, in an O-shaped manner.
Catheters were removed on the 10th (10-25) day of the operations. Data were collected by a third party in 120 consecutive patients prospectively including demographic, surgical, oncological, and functional outcomes with up to 4-year follow-up. Continence was defined as no use of the pad. The patients who were continent on the day of catheter removal were defined as "immediately continent," and those who became continent in the first 3 months were defined as "early continent". Urinary continence was evaluated with a voiding diary and 1-hour pad test before the operation, on the day of catheter removal, and at the end of the first and third months. Early continent definition was also based on the respective answers to the questions "Do you have a problem with dripping or leaking urine?", "Over the last 4 weeks how often have you leaked urine?" (9).

Continence status of the patients was analyzed according to different age groups in order to evaluate a possible relation between patient age and continence rate. Age groups were classified as $\leq 49,50-59,60$ 69 , and $\geq 70$ years. Statistical analysis was performed by using Fischer's exact test or by Chi-square test (GraphPad Prism 4, La Jolla, CA). A p value of $\leq 0.05$ was considered significant.

\section{RESULTS}

In 120 RPP patients, the mean age was 62 (48-75) years and the mean PSA level was 7.4 (1.521) $\mathrm{ng} / \mathrm{mL}$. Of 120 patients, the clinical stage was cT1a in $1(0.8 \%)$, cT1c in $100(83.3 \%)$, cT2 in 19 $(15.8 \%)$. The average Gleason score of patients was $6(4-7) / 10$. Four patients had LPLND in a different surgery before RPP because of PSA which was $>10$ $\mathrm{ng} / \mathrm{mL}$. The mean duration of the operations was 120 (90-270) minutes. While the nerve-sparing technique was applied in $73(60.8 \%)$ as bilateral and $12(10 \%)$ as unilateral, the non-nerve-sparing technique was used in 35 patients (29.2\%). Patients were followedup 24 (3-48) months in outpatient clinics. Early continence rates were $79.4 \%$ in the patients receiving the bilateral nerve-sparing technique and $58.3 \%$ in the unilateral technique $(\mathrm{p}=0.62)$. In the group of patients on whom non-nerve-sparing technique was performed, the early continence rate was $54.2 \%$ ( $p$ 


\section{Perineal Prostatectomy and Early Continence}

$=0.25$ (bilateral vs. non-nerve-sparing)). The mean duration of hospitalization was 1.8 (1-8) days, and catheter-indwelling time was 10 (10-25) days. Of 120 patients, the pathological stage was pT2 in 103 $(85.8 \%)$, pT3 in $14(11.7 \%)$, and pT4 in $1(0.8 \%)$. The overall incidence of positive margins was found in $9.1 \%(11 / 120)$ of all surgical specimens. The incidence of margin involvement at the bladder neck, the anterior prostate, the lateral and apical prostate was $4,3,3$, and 1 case, respectively. Demographic and clinical features of the patients are presented in Table-1.
Forty-four of the 120 patients $(36.7 \%)$ had immediate continence. At the end of first and third months, $65(54.1 \%)$ and 87 of $120(72.5 \%)$ patients, respectively, became early continent. Thirteen patients were out of follow-up after 9 months. At the one-year follow-up, $95.3 \%$ of 107 cases whose one-year follow-up data were available were continent (Figure-1). Evaluation of the relation between patient age and continence status revealed that the early continence rates were found as $77.7 \%, 73.3 \%, 73.4 \%$, and $64.7 \%$ in $\leq 49,50-59,60-69$, and $\geq 70$ years age groups, respectively $(\mathrm{p}=0.68)$.

Table 1 -Data for 120 localized prostate cancer patients who underwent radical perineal prostatectomy.

$\begin{array}{lc}\text { Preoperative Data } & \\ \text { Mean years age (range) } & 62(48-75) \\ \text { Mean PSA (ng/mL) } & 7.4(1.5-19.8) \\ \text { Clinical stage } & \\ \text { cT1a } & 1(0.8 \%) \\ \text { cT1c } & 100(83.3 \%) \\ \text { cT2 } & 19(15.8 \%) \\ \text { cT2 } & --- \\ \text { Peroperative Data } & \\ \text { Mean minutes of operation duration (range) } & 120(90-270) \\ \text { No. nerve sparing (\%) } & \\ \text { Bilateral } & 73(60.8 \%) \\ \text { Unilateral } & 12(10 \%) \\ \text { Non-nerve-sparing } & 35(29.2 \%) \\ \text { Complications } & \\ \text { Mean blood loss in mL (range) } & 270(100-1500) \\ \text { No. of patients rectal injury (\%) } & 3(2.5 \%) \\ \text { Postoperative Data } & \\ \text { Days hospital stay (range) } & 1.8(1-8) \\ \text { Catheterization days (range) } & 10(10-25) \\ \text { No. of patients with prolonged drainage (\%) } & 2(1.7) \\ \text { No. of pathological stage (\%) } & \\ \text { pT0 } & 2(1.7 \%) \\ \text { pT2 } & 103(85.8 \%) \\ \text { pT3 } & 14(11.7 \%) \\ \text { pT4 } & 1(0.8 \%) \\ \text { Surgical margin positivity } & 11(9.1 \%)\end{array}$

PSA $=$ Prostate-Specific Antigen 


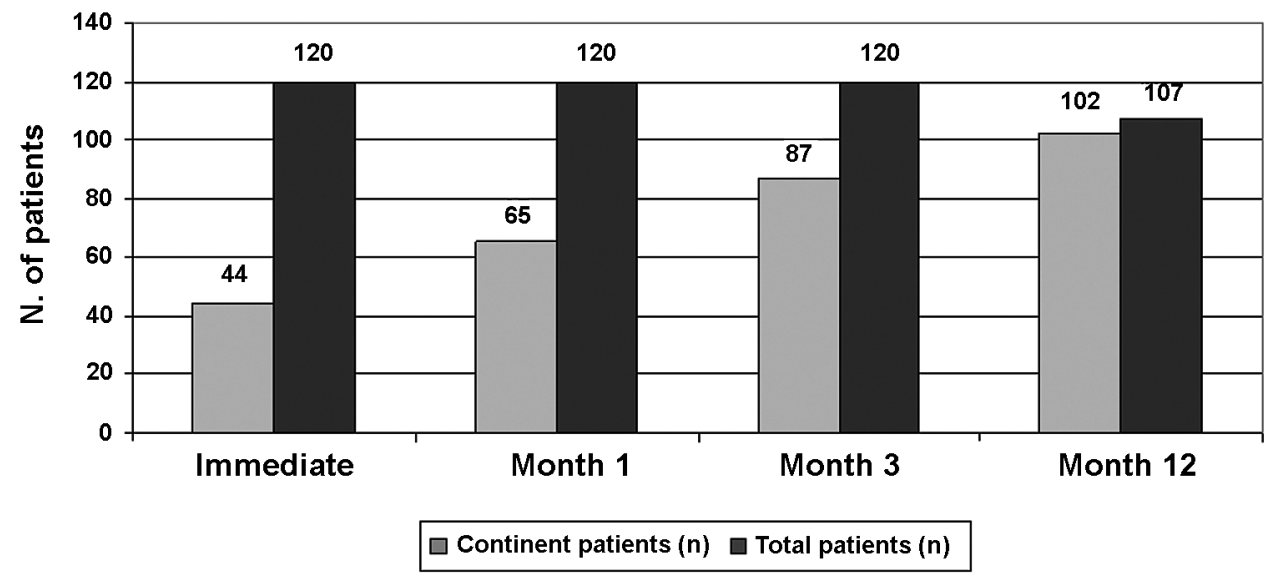

Figure 1 - Continence outcome after radical perineal prostatectomy.

\section{COMMENTS}

RPP has been previously reported to represent an effective treatment for localized adenocarcinoma of the prostate with good functional and oncological outcomes $(1,2)$. However, urinary incontinence still represents a clinically important complication after RPs for prostate cancer. Its incidence ranges widely, from $4 \%$ to $40 \%, 12$ months after RP $(6,10)$.

We provided a prospective assessment of urinary continence of patients who had undergone RPP. In this study, we characterized urinary continence according to definitions of immediate and early with no pad usage. Urinary continence was regained in $36.7 \%$ of patients the day of catheter removal, $54.1 \%$ after one month, $72.5 \%$, after 3 months, and 95.3\% after 12 months. Previous studies showed that continence recovery was achieved in up to $96 \%$ of patients $(5,9-11)$.

In order to evaluate the degree of continence, we defined the use of a pad with 2 questions used by Young et al. (9). In addition to these questions, we obtained voiding diary and 1-hour pad test results. However, as a precaution against possible dripping, several patients had used pads unnecessarily for a few days, even though there was no, not even minimal, incontinence. On the other hand, some of patients did not use a pad despite some degree of incontinence. These variations may partly explain the differences between our results and those in the literature addressing post-RP incontinence.
Previous studies showed that there are some risk factors for post-RP urinary incontinence. Particularly the age of the patient, experience of the surgeon, history of transurethral resection of the prostate surgical technique, and extent of the disease are major determinants of urinary incontinence rates after RP $(8,12,13)$. Furthermore, the possible mechanisms of urinary incontinence after RP include damage of the pelvic floor and urinary sphincter, damage to pelvic floor innervation, and loss of anterior urethral support (14). The fibers of the external urinary sphincter originate dorsally from a point very near the bladder neck and lie on the anterolateral of the urethra in a horseshoe shape ending even with the prostatic apex (14). Previous studies demonstrated that there is a direct relation between protecting surgical anatomic structures (e.g., puboprostatic ligament, sphincter, and periprostatic fascias) and continence rates while performing RPs $(6,15)$.

An anatomical study showed that fine nerve fibers pass from the neurovascular bundles to the external urinary sphincter at the prostatic apex (16). Hollabaugh et al. revealed that the nerves to the external urinary sphincter were most prone to injury when a right angle clamp was used to develop a plane between the posterior external urinary sphincter and anterior rectum (16). In addition, Burnett et al. demonstrated that external urinary sphincter muscle fibers were oriented in vertical and anterolateral di- 
rections with attachments to the subpubic fascia and the medial fascia of the levator ani (17). In order to increase continence rates, retropubic-approaching RP techniques (open, laparoscopic, and robotic-assisted) have been developed using technical modifications to the standard anatomical procedure described by Walsh et al. (8). Nielsen et al. found that "high anterior release" of the levator fascia in open RRP provided excellent oncological results and was associated with improved functional results (18). In laparoscopic and robot-assisted RPs, "curtain dissection" of the lateral prostatic fascia was considered similar to high anterior release (15).

The "Veil of Mystery" technique with preservation of the prostatic fascia seems to reduce significantly the number of nerves present on the specimen, offering consistent quantitative data as a good nerve-sparing technique (15). Furthermore, Takena et al. showed that preservation of the puboprostatic collar and puboperineoplasty contributed to the early recovery of urinary continence after robotic-assisted RP (14). Therefore, all modified retropubic-approaching techniques seek to reduce damage or repair what they damaged. If these injuries are minimal, the continence mechanisms will recover gradually. However, it is impossible to recover all of them immediately because of the nature of the anatomy around the prostate. The difference of the perineal approach arises at this point. Surgical anatomy of the prostate helps to preserve the integrity of puboprostatic collar and endopelvic fascias after RPP. The perineal approach avoids the "Veil of Mystery," and the risk of injuring neurovascular bundle is lessened $(2,4)$. In addition, reports have demonstrated comparable results between RPP and RRP $(7,19)$. Furthermore, RPP is much less expensive and faster to perform, and does not require a new technical set of operative skills, thereby, minimizing the learning curve $(2,4)$.

The most critical region of the continence mechanism, the prostatic apex, is located in a relatively closer plane to the surgeon during RPP, and this location makes apical dissection on the rectal side possible by offering a safe window of exposure. In addition to difficulties during dissection, an effort to make an anastomosis in an insufficient exposure carries the risk that the fibers of the external urinary sphincter may be compressed under the anastomotic suture line, possibly causing the external urinary sphincter to lose the strength required to obstruct the urethra. Tensionfree anastomosis with mucosal-to-mucosal coaptation and proper urethral alignment should be aimed. The proximity of the prostate to the perineum, which is about $5 \mathrm{~cm}$, when the patient is in the exaggerated lithotomy position is the main advantage of the RPP (4). Consequently, this anatomical feature provides optimal exposure for accurate vesicourethral anastomosis by easily stitched sutures and avoiding nearby tissues e.g. external urinary sphincter. Vesicourethral anastomosis is performed with running or interrupted sutures in RPs $(4,11,20)$.

Harris et al. showed that running anastomosis was associated with a $1 \%$ incidence of anastomotic strictures compared to a $1.9 \%$ incidence when using interrupted anastomosis (11). Harris et al. demonstrated that the median catheter time with a running anastomosis was 8 days as opposed to 17 days for an interrupted anastomosis (11). In our study, we had two $(1.7 \%)$ patients with prolonged urinary drainage lasting 14 and 18 days. We left their transurethral catheters in an additional week and took a cystogram before catheter removal to ensure no extravasation.

It is well known that surgical experience influences postoperative incontinence rates. In many of the related studies, authors found that surgical experience and technical refinements resulted in a decrease in incontinence rates $(8,13)$. It has been demonstrated that RPP was learned at least as easily as retropubic prostatectomy (19).

This study observed that age is an important predictor of regaining immediate continence. In our study, the rate of immediate continence was significantly lower with older ages. It has been demonstrated that, with increasing age, atrophy and neuronal degeneration occurs in the external urinary sphincter $(16,17)$. Catalona et al. found that the recovery of urinary continence was associated with younger age but not with tumor stage or nerve-sparing surgery (21). Similar to that study, this study found no relation between the stage and continence. There are some potential limitations to our study that should be considered. First, the study had an observational nature. Second, we focused single outcome of continence without reporting of sexual function and oncological outcomes. We considered that we could discuss single 
outcome of continence in detail. We also did not apply questionnaire as 50-item Expanded Prostate Cancer Index Composite (22). However, we mainly focused on pad usage and problem with dripping or leaking urine. We applied voiding diary and 1-hour pad test and two questions, which were easy to apply and offered precise answer.

In this study, majority of patients regained urinary continence within 12 months after RPP. Our data suggest that age, pathological stage and preservation of the neurovascular bundles had no significant influence on preservation of urinary control. Early continence rate was higher in the bilateral nerve-sparing group relative to the unilateral and non-nervesparing groups; while the difference did not reach statistical significance. This can be explained due to a small number of patients included in unilateral and non-nerve-sparing groups. We believe that anatomical factors rather than preservation of autonomic innervation may be responsible for the improved urinary control associated with an anatomical approach to RP. When the anatomical relations of the structures of continence are considered, the external urinary sphincter and surrounding tissue can be protected from surgical trauma more easily in RPP technique when compared to other RPs.

RPP, in experienced hands, remains the most cost-effective procedure, with lower operative costs and shorter times (19). The lack of LPLND seems a major disadvantage of RPP. However, in many cases, using the PSA, Gleason score, and clinical stage can determine whether the rate of lymph node metastasis low enough to avoid lymphadenectomy.

\section{CONCLUSION}

A valuable therapeutic modality in localized prostate cancer should have not only excellent oncological results but also flawless functional results. This study outlines the recovery of urinary continence within 12 months after RPP based on evidence from the voiding diary and the one-hour pad test and suggests that, depending on the definition of continence, a majority of patients regain urinary continence early. Moreover, most recovery of urinary continence occurred within the first 3 months. Considering this in- formation, RPP is a good therapeutic option resulting in urinary continence as early as the day of catheter removal or in the early postoperative period. Urologists should be encouraged and trained to offer RPP, particularly in an era of laparoscopic and robotic-assisted treatments of prostate cancer.

\section{CONFLICT OF INTEREST}

None declared.

\section{REFERENCES}

1. Martis G, Diana M, Ombres M, Cardi A, Mastrangeli $\mathrm{R}$, Mastrangeli B: Retropubic versus perineal radical prostatectomy in early prostate cancer: eight-year experience. J Surg Oncol. 2007; 95: 513-8.

2. Janoff DM, Parra RO: Contemporary appraisal of radical perineal prostatectomy. J Urol. 2005; 173: 1863-70. Erratum in: J Urol. 2005; 174: 1505.

3. Frota R, Turna B, Barros R, Gill IS: Comparison of radical prostatectomy techniques: open, laparoscopic and robotic assisted. Int Braz J Urol. 2008; 34: 259-68; discussion 268-9.

4. Melman A, Boczko J, Figueroa J, Leung AC: Critical surgical techniques for radical perineal prostatectomy. J Urol. 2004; 171: 786-90.

5. Bishoff JT, Motley G, Optenberg SA, Stein CR, Moon KA, Browning SM, et al.: Incidence of fecal and urinary incontinence following radical perineal and retropubic prostatectomy in a national population. $\mathrm{J}$ Urol. 1998; 160: 454-8.

6. Steiner MS, Morton RA, Walsh PC: Impact of anatomical radical prostatectomy on urinary continence. J Urol. 1991; 145: 512-4; discussion 514-5.

7. Lance RS, Freidrichs PA, Kane C, Powell CR, Pulos E, Moul JW, et al.: A comparison of radical retropubic with perineal prostatectomy for localized prostate cancer within the Uniformed Services Urology Research Group. BJU Int. 2001; 87: 61-5.

8. Walsh PC, Partin AW, Epstein JI: Cancer control and quality of life following anatomical radical retropubic prostatectomy: results at 10 years. J Urol. 1994; 152: 1831-6.

9. Young MD, Weizer AZ, Silverstein AD, Crisci A, Albala DM, Vieweg J, et al.: Urinary continence and quality of life in the first year after radical perineal prostatectomy. J Urol. 2003; 170: 2374-8. 
10. Matsubara A, Yasumoto H, Mutaguchi K, Mita K, Teishima J, Seki M, et al.: Impact of radical perineal prostatectomy on urinary continence and quality of life: a longitudinal study of Japanese patients. Int J Urol. 2005; 12: 953-8.

11. Harris MJ: The anatomic radical perineal prostatectomy: an outcomes-based evolution. Eur Urol. 2007; 52: 81-8.

12. Kübler HR, Tseng TY, Sun L, Vieweg J, Harris MJ, Dahm P: Impact of nerve sparing technique on patient self-assessed outcomes after radical perineal prostatectomy. J Urol. 2007; 178: 488-92; discussion 492.

13. Eastham JA, Kattan MW, Rogers E, Goad JR, Ohori $\mathrm{M}$, Boone TB, et al.: Risk factors for urinary incontinence after radical prostatectomy. J Urol. 1996; 156: 1707-13.

14. Takenaka A, Tewari AK, Leung RA, Bigelow K, El-Tabey N, Murakami G, et al.: Preservation of the puboprostatic collar and puboperineoplasty for early recovery of urinary continence after robotic prostatectomy: anatomic basis and preliminary outcomes. Eur Urol. 2007; 51: 433-40; discussion 440.

15. Savera AT, Kaul S, Badani K, Stark AT, Shah NL, Menon M: Robotic radical prostatectomy with the "Veil of Aphrodite" technique: histologic evidence of enhanced nerve sparing. Eur Urol. 2006; 49: 1065-73; discussion 1073-4.

16. Hollabaugh RS Jr, Dmochowski RR, Kneib TG, Steiner MS: Preservation of putative continence nerves during radical retropubic prostatectomy leads to more rapid return of urinary continence. Urology. 1998; 51: 960-7.

17. Burnett AL, Mostwin JL: In situ anatomical study of the male urethral sphincteric complex: relevance to continence preservation following major pelvic surgery. J Urol. 1998; 160: 1301-6.

18. Nielsen ME, Schaeffer EM, Marschke P, Walsh PC: High anterior release of the levator fascia improves sexual function following open radical retropubic prostatectomy. J Urol. 2008; 180: 2557-64; discussion 2564.

19. Burgess SV, Atug F, Castle EP, Davis R, Thomas R: Cost analysis of radical retropubic, perineal, and robotic prostatectomy. J Endourol. 2006; 20: 827-30.

20. Mazaris EM, Chatzidarellis E, Varkarakis IM, Dellis A, Deliveliotis C: Reducing the number of sutures for vesicourethral anastomosis in radical retropubic prostatectomy. Int Braz J Urol. 2009; 35: 158-63.

21. Catalona WJ, Carvalhal GF, Mager DE, Smith DS: Potency, continence and complication rates in 1,870 consecutive radical retropubic prostatectomies. J Urol. 1999; 162: 433-8.

22. Wei JT, Montie JE: Comparison of patients' and physicians' rating of urinary incontinence following radical prostatectomy. Semin Urol Oncol. 2000; 18: 76-80.

\section{Correspondence address:}

Dr. Onder Canguven

Sakac1 sokak 34/5 Yildiz apt.

Kozyatagi, Kadikoy

Istanbul, 34738, Turkey

E-mail: ocanguven@yahoo.com 